\title{
The Cholesteryl Octanoate Breath Test: A New Procedure for Detection of Pancreatic Insufficiency in the Rat
}

\author{
SIFHAN MUNIDIOS. JAMFS B. RHOHES. ANI) AIAN F. HOHMANX

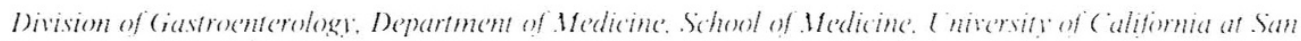

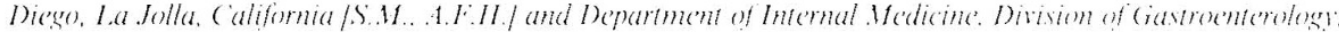 \\ Liniversity of Kansas: Kansas ( il!: Kansas /.J.B.R./
}

\begin{abstract}
ABSIRACI. A breath test for the detection of pancreatic insufficiency was developed and tested in rats. The test features the hydrophobic molecule cholesteryl-1-14C-octanoate, which liberates 14C-octanoic acid when hydrolyzed by carboxyl ester lipase (cholesterol esterase). The 14C-octanoate is absorbed passively and rapidly metabolized to $14 \mathrm{CO}_{2}$, which is excreted in expired air. The compound was administered as an emulsion of cholesteryl octanoate, triglyceride, and lecithin to rats with mild pancreatic insufficiency induced by injecting the pancreatic duct with zein. The animals had exocrine pancreatic hypofunction based on the enzyme content of pancreas at autopsy. Amylase was reduced by $97.1 \pm 1.4 \%$, whereas chymotrypsin was reduced by $73 \pm 14 \%$. The $p$-aminobenzoic acid test was abnormal at 1 wk $(21.68 \pm 8.4 \%)$, but become normal at 3 months $(72.08 \pm 5.8 \%)$ after zein injection. Despite this, the animals gained weight and absorbed fat normally. The $14 \mathrm{CO}_{2}$ excretion rate in the 110-min interval after feeding was significantly reduced to $60 \%$ of sham-operated animals. Peak $14 \mathrm{CO}_{2}$ collections $20 \mathrm{~min}$ after feeding were reduced by $75 \pm 11 \% .14 \mathrm{CO}_{2}$ output was completely normalized by administration of pancreatin prior to the test meal. The results suggest that a sensitive, noninvasive method for detecting deficiency of pancreatic carboxyl ester lipase (cholesterol esterase) secretion in the rat has been developed. (Pediatr Res 22: 257-261, 1987)
\end{abstract}

Abbreviations

NB'I-PABA, N-benzoyl-I-tyrosyl-p-aminobenzoic acid TIC, thin-layer chromatography

The diagnosis of pancreatic disease, particularly in cases of cystic fibrosis or other congenital abnormalities of the pancreas. remains a continuing problem. The conventional procedure to assess pancreatic function requires the measurement of total fatty acids in stool samples collected for 3 to 4 days. This procedure is not only inconvenient and cumbersome for the parents, it is also difficult to perform in infants who are not toilet trained. Furthermore, the presence of fat malabsorption is likely to be a rather late symptom, since steatorrhea does not occur in adults

Received June 19, 1986; accepted March 27, 1987

Correspondence and reprint requests Stefan Mundlos. M.D.. Klinik der Johannes, (iutenberg-Universitat, Department of Pediatrics. Iangenteckstr. 1, 6500 Mainz, F.R.C;

Supported by (irant AM 21506 to A.F.H. from National Institutes of Health S.M. was a recipient of a Student Summer Fellowship $\wedge$ ward from the American Gastroenterological Association. until severe pancreatic insufficiency. manifested by a $9(0)$ reduction in ensme secretion. is present (1). At this stage the diagnosis is usually obvious because of the presence of steatorrhea or other manifestations of the disease. Conseguently. the diagnostic chatlenge is to detect pancreatic disease before severe malabsorption occurs.

It is agreed that the most reliable method of assessing pancreatic function involves duodenal intubation for direct measurement of pancreatic enzymes after stimulation with cholecystokinin-secretin. secretin. or l.undh meal. This approach is not only invasive. time consuming. and expensive, it is especially difficult to perform in children. Thus. many have attempted to develop a noninvasive, easy, and sensitive test to assess pancreatic function (2). For some vears a number of investigators have been exploring the utility of breath tests. attracted by their simplicity and low cost (3). In 1962. Schwabe "' al. (4) reported promising results with a $14 \mathrm{CO}_{2}$ breath test using trioctanoin. A comprehensive study by Newcomer et al. (5) showed that a 14C(), test based on triolein gave better results. The triolein test was sensitive. but likely to give false-positive results in biliary and intestinal discase. In addition. the test required 4 to $6 \mathrm{~h}$ to perform and had considerable radiation hazard.

The present study was performed to develop a new breath test for measurement of intraluminal fat digestive activity and in particular to assess the feasability of a $14 \mathrm{C}(\mathrm{O})$, breath test based on the hydrolysis of cholesteryl-1-14C-octanoate as a new marker for exocrine pancreatic function.

\section{MFIHODS}

Principle of the test. A graphic illustration of the cholesteryl octanoate breath test is shown in Figure 1. The test molecule cholesteryl-1-14C-octanoate is a cholesterol ester with an 8-chain fatty acid in the ester position. After ingestion. the marker is hydrolyzed by pancreatic carboxyl ester lipase (cholesterol esterase) to cholesterol and 14C-octanoic acid. Octanoate is then passively and rapidly absorbed by the intestinal mucosa. transported without prior esterification via the portal vein to the liver and oxidized to $14 \mathrm{CO}_{2}$. The rate at which $14 \mathrm{CO}$, is expired, is assumed to be proportional to the rate of hydrolysis of the marker. $i . e$. in the multiple steps between ingestion of the compound and its recovery as $14 \mathrm{CO}_{2}$ in breath, esterolysis is hypothesized to be rate limiting.

Male Sprague-Dawley rats weighing between 280 and $340 \mathrm{~g}$ were used. They were housed separately in regular cages with free access to water and a standard pellet diet.

Pancreatic exocrine hypofunction was induced according to Rhodes et al. (6). After an overnight fast, the animals were anesthetized with an intraperitoneal injection of sodium pentobarbital $(3 \mathrm{mg} / 100 \mathrm{~g})$ and the abdomen was opened by a midline incision. 


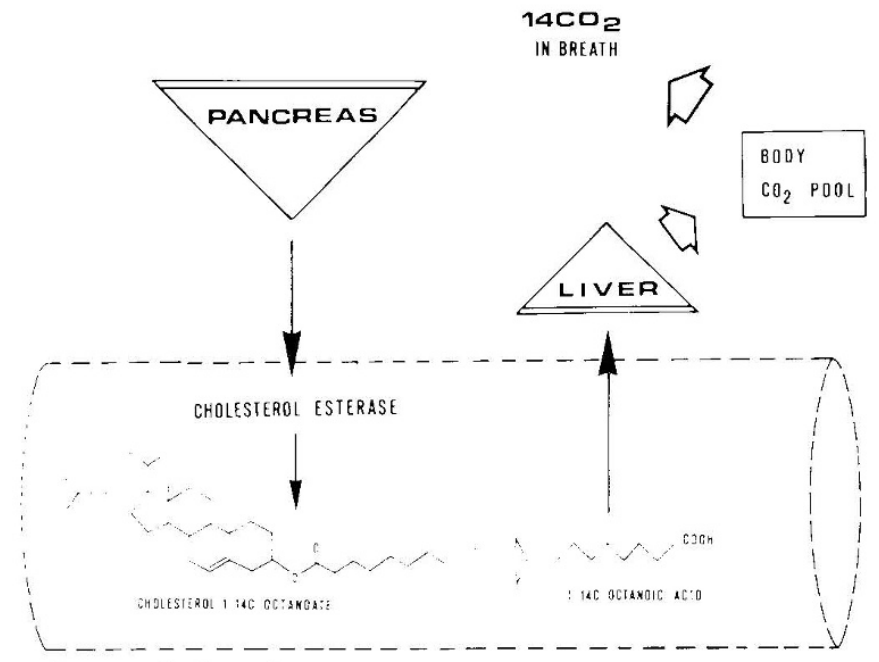

Fig. 1. Principle of the cholesteryl-1-14C-octanoate breath test for the detection of pancreatic exocrine hypofunction.

The pancreas was identified and a silk suture was passed under the duct near the duodenum for stabilization and temporary occlusion. The biliary duct proximal to the junction of the biliary and pancreatic ducts was occluded temporarily with a forceps to prevent the zein solution from entering the liver. The zein solution $(0.1 \mathrm{ml} / 100 \mathrm{~g}$ of rat $)$ was injected into the distal duct through a 27 -gauge needle attached to a syringe. After closing the abdomen, the animals were returned to their individual cages. Water and food were again offered ad libitum. Sham-operated rats served as control animals. The zein solution contained per ml $37 \mathrm{mg}$ zein (Sigma, St. Louis, MO) dissolved in $0.1 \mathrm{ml}$ of $95 \%$ ethanol and suspended in $0.9 \mathrm{ml}$ of linoleic and oleic acids $(2: 1 \mathrm{v} / \mathrm{v})($ Sigma).

To confirm pancreatic hypofunction, a NBT-PABA test was performed $1 \mathrm{wk}$ after the injection of the zein solution. The animals were fasted over night and $1 \mathrm{mg} / 100 \mathrm{~g}$ rat of Bentiromide (N-benzoyl-L-tyrosyl-paraaminobenzoate) in $2 \mathrm{ml}$ solution was injected in the stomach through a blunt tipped metal cannula passed down the esophagus. Food and water were offered ad libitum after gastric injection and urine was collected for $24 \mathrm{~h}$. Urine paraaminobenzoic acid was determined by the BrattonMarshall reaction after acid hydrolysis (7).

Before breath testing, the animals were kept for 3 months in individual cages with free access to a standard pellet diet, to give time for possible intestinal adaptation to pancreatic hypofunction. After this time interval, the cholesteryl-1-14C-octanoate breath test was performed, and pancreatic function was determined by measurement of NBT-PABA excretion and fat absorption. The animals were then sacrificed, and the chymotrypsin and amylase content in total pancreatic homogenate was determined.

Considerable care was taken to develop a method of emulsifying the practically water-insoluble cholesteryl octanoate in such way that the emulsion was stable and the particle size was small. Preliminary experiments indicated that the nature of the emulsion markedly influenced $14 \mathrm{CO}_{2}$ output. The optimal result, i.e. the greatest recovery of $14 \mathrm{CO}_{2}$, was obtained by using $1: 10: 12$ $(\mathrm{w} / \mathrm{w} / \mathrm{w})$ proportions of cholesteryl octanoate, triglyceride, and lecithin. To prepare the emulsion, $5 \mathrm{mg}$ cholesteryl octanoate, $50 \mathrm{mg}$ triglyceride, and $60 \mathrm{mg}$ lecithin were dissolved in chloroform in a $20-\mathrm{ml}$ glass liquid scintillation vial. The chloroform was evaporated under a $\mathrm{N}_{2}$-stream so that the substrate remained as a thin layer adherent to the bottom of the vial. Two and onehalf $\mathrm{ml}$ of $\mathrm{NaCl} 0.9 \%$ were added, and the solution was sonicated in a Brownwill Biosonic (Brownwill Scientific, Rochester, NY) for $20 \mathrm{~min}$ with an energy output of $200 \mathrm{~W}$ in an ice bath under an $\mathrm{N}_{2}$ stream (test meal I). The test meal was freshly prepared for each set of experiments, using this technique. The radioactiv- ity concentration of the emulsion was measured prior to administration of the test meal.

To exclude impaired absorption and/or metabolism of octanoate in zein-injected rats, a test meal containing the products of hydrolysis of cholesteryl octanoate $(1.9 \mu \mathrm{mol}$ cholesterol and $1.9 \mu \mathrm{mol} 14 \mathrm{C}$-octanoic acid) was administered as a positive control (test meal II). Preparation of the test meal was identical to the one described above.

Another positive control was performed by feeding zein-injected rats with pancreatic enzymes 5 min prior to administration of test meal I. Pancreatic enzymes consisted of $1 / 4$ capsule Cotazyme which was equal to 2000 USP units lipase, 7500 USP units protease, and 7500 units amylase. The capsule was suspended in $5 \mathrm{ml}$ of isotonic saline (test meal III).

Animals were fasted over night prior to each experiment. After administration of $0.5 \mathrm{ml}$ of the test meal, containing $1 \mathrm{mg}$ of cholesteryl octanoate $(200,000 \mathrm{dpm})$ by an intragastric tube, the animals were immediately placed in the glass cage of the $\mathrm{CO}_{2}$ trapping train.

Test meal I (cholesteryl-14C-octanoate), test meal II (cholesterol and 14C-octanoic acid), and test meal III (cholesteryl-14Coctanoate and pancreatin) were administered to zein-injected rats, whereas control animals received only test meals I and II.

The $\mathrm{CO}_{2}$ trapping train consisted of a glass cage for the animal with a volume of 1.8 liter and four gas bubblers connected by tubing to a vacuum line. The trapping solution in the bubbler consisted of $5 \mathrm{ml}$ ethanolamine and methoxyethanol $(1: 1 \mathrm{v} / \mathrm{v})$. $\mathrm{CO}_{2}$ trapping was highly efficient, leading to a $95 \%$ retention of radioactivity in the first bubbler and more than $4 \%$ in the second bubbler. Less than $1 \%$ of radioactivity was lost. Samples were counted after adding $4 \mathrm{ml}$ of methanol and $10 \mathrm{ml}$ of a Toluenebased scintillation cocktail (Aquasol NEN) to the trapping fluid. Counts were converted to disintegrations per min by external standardization. The results were expressed either as percentage of administered dose per min or as cumulative recovery in percent of administered dose.

For feces collection, animals were housed in individual metabolic cages with free access to water and a standard diet containing $6 \%$ fat. After 3 days, feces were collected and food intake was measured for 3 days. The 3-day stool was pooled, freeze dried, and investigated for fecal fat according to Jover and Gordon (8).

For in vitro amylase and chymotrypsin measurements the rats were sacrificed using ether and the pancreas was removed. The tissue was homogenized in $5 \mathrm{ml}$ isotonic saline at $4^{\circ} \mathrm{C}$. Amylase activity was estimated in the total pancreatic homogenate using the starch-iodine procedure (9), and chymotrypsin activity was measured with bentiromide after trypsin activation (10).

Cholesteryl-1-14C-octanoate was synthesized and supplied by Dr. Herok of Hoechst AG, Frankfurt/Main, West Germany. Radiopurity was checked by TLC, HPLC and GC and was found to be $99 \%$. The specific activity was $22.4 \mathrm{mCi} / \mathrm{g}$.

Nonradioactive cholesteryl octanoate was synthesized by reacting cholesterol with octanyl chloride in water-free pyridine. The product was purified by several recrystallization steps in ethanol and its purity was checked by TLC. Lecithin was prepared from hen's egg yolk according to Singleton et al. (11). For preparation of the test meal, cholesterol-free vegetable oil was used. Cholesterol A grade was obtained from CalBioChem and $14 \mathrm{C}$-octanoic acid was purchased from NEN. Statistical analysis was conducted using the Wilcoxon rank sum test.

\section{RESULTS}

Figure 2 shows the $14 \mathrm{CO}_{2}$ recovery over a 110 -min period expressed as percent of dose administered after feeding $1 \mathrm{mg}$ of 14C-labeled cholesteryl octanoate (test meal I) to zein-injected rats and control animals. The appearance of $14 \mathrm{CO}_{2}$ in the breath of control animals was very rapid, leading to a peak of radioactivity output as soon as $10-20 \mathrm{~min}$ after feeding. In contrast to these findings, $14 \mathrm{CO}_{2}$ output in zein-injected rats increased slowly after feeding; in most rats peak collections were delayed 


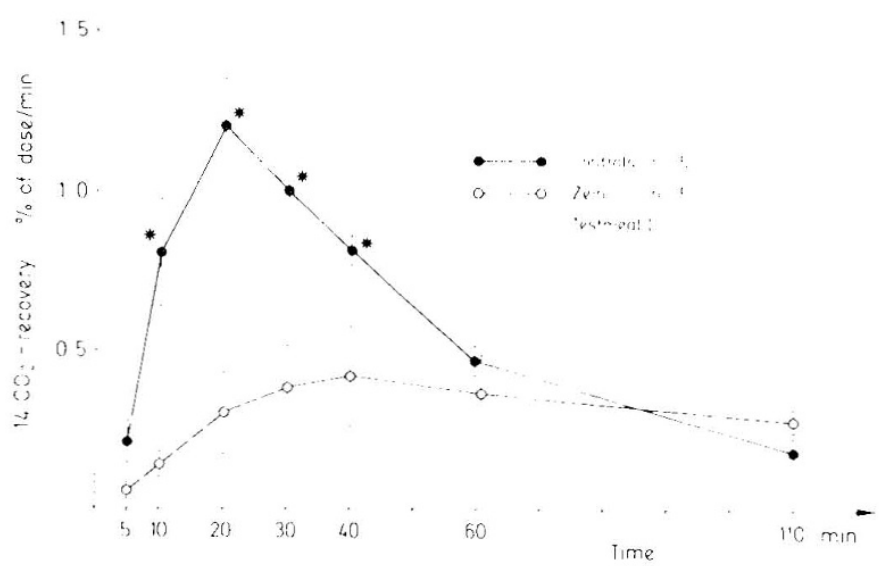

Fig. 2. 14( (), recovery rate ( 4 dose/min) after administration of test meal I (cholesteryl-1-14('-octanoate) in cein-injected rats rersus shamoperated control animals. ${ }^{*} P<0.0 \mathrm{i}$ : mean $\left.\pm \mathrm{SI}\right)$.

until the fourth to sixth collection interval. At this time peak excretion was still less than half that of control animals. $1.40^{\circ}()$. excretion $20 \mathrm{~min}$ after feeding was significantly reduced to $25 \pm$ $11 \%$ of control values in $x$ ein-injected animals

rigure 3 shows the effect of feeding pancreatin prior to the test meal on the $140^{\circ}()$, recovery in ein-injected rats. Values obtained without pancreation supplementation are also shown. The time course and rate of $14\left(^{\circ}()\right.$, output were restored fully to control values by ensyme supplementation.

The results of $14($ () excretion after feeding hydrolyed substrate (test meal II) are shown in ligure 4. Vo difference was seen between controls and sein-injected animals. indicating that absorption and metabolism of octanoic acid was not impaired in animals with pancreatic insufficiency. (ontrols showed no significant difference between $140^{\circ}()$, recovery after test meal I. when compared to lest meal II.

Cumulative recovers of radionetivis after ? $20 \mathrm{~min}$ or after 1.0 min is shown in bigure 5 after feeding different lest meals wo control animals and rein-injected rats. The overall recosers in zein-injected rats was reduced by 40$)^{\prime}$; after administration of test meal 1. Feeding test meal $11 \quad(1.9 \mu m o l$ cholesterol and 1.9 $\mu$ mol 146-octanoic acid) fully restored 14(0). recosery in 2 ininjected rats to control values. In rein-injected rats $14\left(\right.$ ( ) $^{\circ}$ ) output was practically identical to control animals when pancreatic ensymes were administered prior to feeding cholesteryl octanoate (test meal III).

All experiments were performed in duplicate. There was an overall variation in total recovery within one animal of fess than 4.6\% and between different animals (eontrols) of less than $5.1 \%$.

lable 1 summaries the results of the fecal fat measurements and the $\triangle B I-P \wedge B \wedge$ test. I he fat absorption of $/$ cin-injected rats was $95.7+2.34$ and in the sham-operated animals it was 96.8 $\pm 0.5 \%$. The difference was not signiticant.

The results of the $\backslash B$ I-P $\triangle B \wedge$ test. expressed as perecentage of dose recovered in $24 \mathrm{~h}$. showed a signilicant difference between control animats and ein-injected rats 1 wh after injection of the zein solution. Three months after the operation. the results were similar in the two groups and no statistical significant difference was found. One wh after operation. ein-injected rats exereted $21.68+8.4 \%$, whereas 3 months after operation PABA cxcretion wals $7208+5.84$

The cosyme content of the lotal pancreatic homogenate showed a considerable degree of reduction in exocrine lunction (Table 2). Amstase was reduced by $97 \pm 1.4 \%$. While chy motrypsin was reduced by $71+14 \%$ in rein-injected rats when compared to control values.

\section{1) IS( Tission.}

Hercin we describe a new breath test for the rapid and simple indirect assessment of pancreatic lipolytic activity in the rat. The

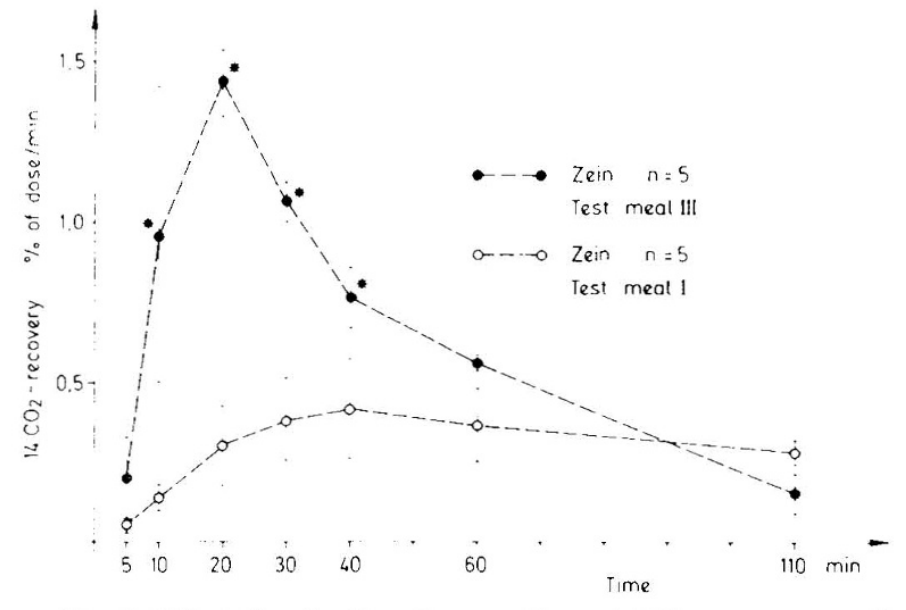

Fig. 3. Feffect of prefeeding of pancreatin on $1.4(0)$. recosery rate dese/min) in ecin-injected rats (test meal III). Data from animals not receiving pancreatin ate also shown (test meal n) ${ }^{*} p<0.01$. IS w control (fig. 2): mean \pm SI)

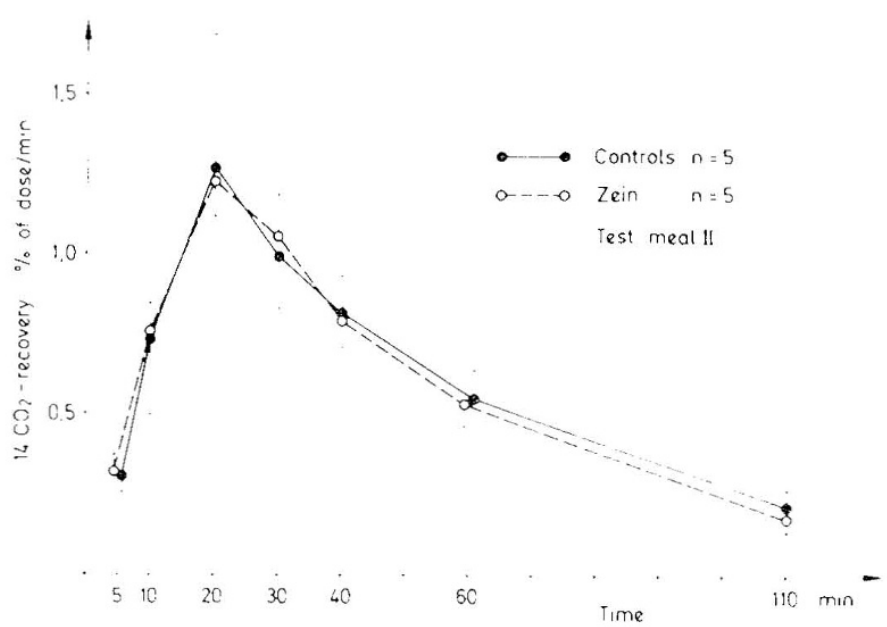

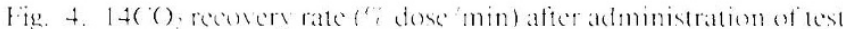

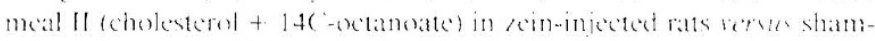
operated controk is to control: mean + SH).
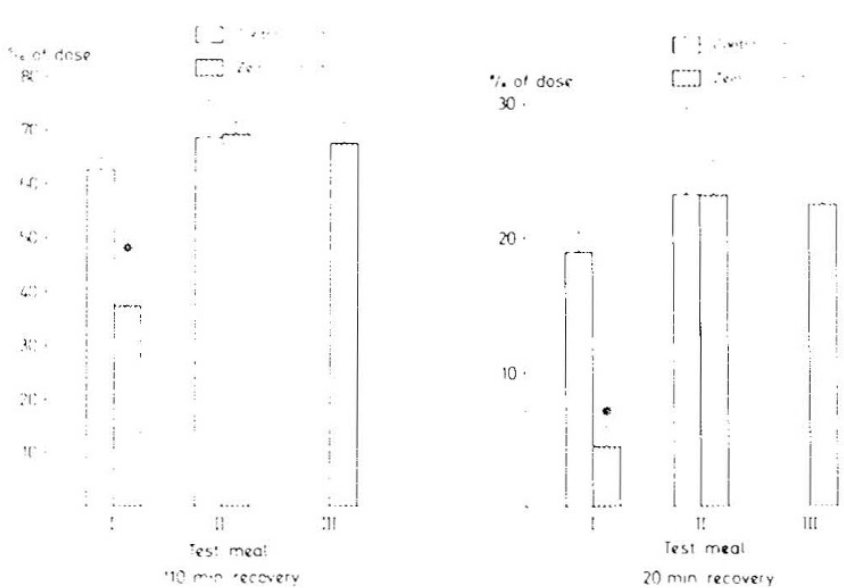

Fig. (umulative $1+C^{\circ}()$. recosery in $20 \mathrm{~min}$ (right) and $1 / 0 \mathrm{~min}$ thefi) in em-injected rats eerus sham-encrated control anmals atter

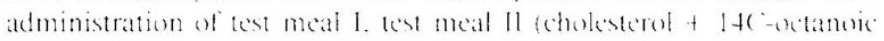

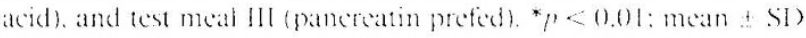

Lest features the hedrophobic molecule cholestery-14t-extanoate. which liberates $140^{\circ}-$ octanoic acid. when hydrolysed by pancreatic carboxyl ester lipase.

(holestery octanoate appears attractive as a test molecule for 
Table 1. Intake and excretion of fatty acids ( $F A)$ ( $m E q /$ day) and excretion of PABA (\%dose/24 h) in zein-injected rats versus sham-operated control animals (mean $\pm S D$ )

\begin{tabular}{|c|c|c|}
\hline & $\begin{array}{c}\text { Zein } \\
(n=5)\end{array}$ & $\begin{array}{l}\text { Control } \\
(n=5)\end{array}$ \\
\hline \multicolumn{3}{|l|}{$\mathrm{FA}(\mathrm{mEq} /$ day $)$} \\
\hline Intake* & $5.48 \pm 0.93$ & $6.09 \pm 1.1$ \\
\hline Excretion* & $0.24 \pm 0.14$ & $0.2 \pm 0.04$ \\
\hline Absorption $(\%)^{*}$ & $95.7 \pm 2.3$ & $96.8 \pm 0.5$ \\
\hline \multicolumn{3}{|l|}{ PABA excretion (\%) } \\
\hline 1 wk after $\dagger$ & $21.68 \pm 8.4$ & $65.0 \pm 9.2 \ddagger$ \\
\hline 3 mo after zein injection* & $72.08 \pm 5.8$ & $65.33 \pm 28.5$ \\
\hline \multicolumn{3}{|l|}{$\begin{array}{l}* \text { NS. } \\
\dagger p<0.01 \\
\ddagger n=8 .\end{array}$} \\
\hline \multicolumn{3}{|c|}{$\begin{array}{l}\text { Table 2. Enzyme content in total pancreatic homogenate in } \\
\text { zein-injected rats versus sham-operated control animals } \\
\text { (mean } \pm S D)\end{array}$} \\
\hline & $\begin{array}{c}\text { Zein } \\
(n=5)\end{array}$ & $\begin{array}{l}\text { Control } \\
(n=4)\end{array}$ \\
\hline \multicolumn{3}{|l|}{ Amylase* } \\
\hline $\mathrm{U} /$ pancreas & $1945 \pm 950$ & $66875 \pm 17918$ \\
\hline$\%$ control & $2.9 \pm 1.4$ & \\
\hline \multicolumn{3}{|l|}{ Chymotrypsinogen* } \\
\hline $\mathrm{U} /$ pancreas & $3.2 \pm 0.5$ & $11.85 \pm 3.37$ \\
\hline$\%$ control & $27 \pm 14$ & \\
\hline
\end{tabular}

pancreatic function for several reasons. In the intestinal lumen, cholesterol esters are hydrolyzed by carboxyl ester lipase (cholesterol esterase) to cholesterol and fatty acid (12), which subsequently can be absorbed through the mucosa (13). Enzymatic hydrolysis of dietary fat begins in the stomach, where $10-40 \%$ of the total dietary triglyceride may be digested (14). In humans and most mammals, the major gastric lipase is lingual lipase, an enzyme secreted from lingual serous glands (15). In contrast to triglycerides, phospholipids and cholesterol esters are resistant to lingual lipase (16). In addition to being present in pancreatic secretion, carboxyl ester lipase activity is also measurable in the intestinal mucosa. This enzymatic activity is believed to be of pancreatic origin, since rats subjected to external drainage of pancreatic juice show an absence of carboxyl ester lipase in the intestine (17). Hence, carboxyl ester lipase is a digestive enzyme secreted mainly, if not exclusively, by the exocrine pancreas. The value of cholesterol esterase as a marker enzyme for exocrine pancreatic insufficiency is supported by the encouraging results with the fluorescein dilaurate test (18), which also measures the activity of carboxyl ester lipase (cholesterol esterase) (19).

Peak recovery of $14 \mathrm{CO}_{2}$ in breath occurred as early as $20 \mathrm{~min}$ after administration of the test meal. The rapid recovery of $14 \mathrm{CO}_{2}$ is believed to be due to the unique properties of octanoic acid, namely its rapid, passive absorption (20) and the absence of esterification in the enterocyte, its transport to the liver in portal blood, and its rapid and complete oxidation in the liver or other tissues (21). In contrast to long-chain fatty acids, which are transported via the thoracic duct, most short-chain fatty acids, i.e. those with less than 12 carbon atoms, are absorbed directly into the portal venous system (22) and do not require bile acids for absorption, since they have considerable water solubility (23). However, pancreatic carboxyl ester lipase does require bile salts to be present at micellar concentration for full enzyme activity (12).

The functional degree of pancreatic insufficiency was determined by the result of fat absorption and the NBT-PABA test, which was performed $1 \mathrm{wk}$ after and 3 months after the injection of zein. Although the enzyme content in pancreatic homogenate revealed a significant degree of pancreatic insufficiency, fat and PABA excretion appeared to be normal at the time of breath testing. The observed shift in PABA excretion from significantly reduced levels right after the injection of zein to control values 3 months later, could be explained in a number of ways. A regeneration of destroyed pancreatic tissue seems unlikely in this model of pancreatic insufficiency (6). Although the NBT-PABA test has been successfully used to assess pancreatic function in humans (24) and rats (7), certain limitations regarding the tests specificity and sensitivity have been reported. PABA excretion was found after exclusion of pancreatic secretions from the intestine in rats (25) and after total pancreatectomy in humans (18). Certain nonpancreatic enzymes of bacterial and mucosal origin were shown to be capable of NBT-PABA hydrolysis (26, $25)$. It could be speculated that in long-standing pancreatic insufficiency bacterial overgrowth and/or adaptation of mucosal enzymes leads to recovery of NBT-PABA hydrolysis.

In zein-injected rats, the reduction of chymotrypsin activity in the pancreatic homogenate was much less pronounced than the reduction of amylase activity. Similar discordant changes of enzyme content were observed in the duct ligation model of pancreatic insufficiency, where amylase was found to be decreased by $54 \%$, while trypsin was reduced by only $33 \%$ (27). In accordance to these findings, we reported in a recent study that the relative content of protease in pancreatic homogenate rises with the degree of pancreatic insufficiency (28). This shift in enzyme production seems to be an adaptive process of the remaining exocrine pancreas to the loss of exocrine tissue. The nonproportional increase of trypsin and chymotrypsin might be another explanation for the insensitivity of the PABA test in this situation.

Zein-injected rats did not show an impairment in fat absorption. Similar observations were made with another model for pancreatic insufficiency. Again, rats with severe pancreatic insufficiency had a normal fat absorption, when fed a standard diet (Mundlos S, Adler G, Hausmann W, unpublished observations) despite a $99 \%$ reduction of lipase activity in pancreatic homogenate. This somewhat surprising capacity of fat digestion in severe pancreatic malfunction might be due to adaptive processes leading to significant lipase production from sites other than the pancreas. In the rat, as well as in humans, lingual lipase and gastric lipase are known to play an important role in fat digestion (15). Initial lipolysis in the stomach by lingual and/or gastric lipase becomes a much more important process in conditions of pancreatic insufficiency and may in part compensate the lack of pancreatic digestive capacity (29). It was suggested that preduodenal, i.e. nonpancreatic digestion, contributes to the assimilation of $60-70 \%$ of ingested fat in children with cystic fibrosis or congenital lipase deficiency (30). Similar adaptive processes in the rat seem likely.

Since the time course of $14 \mathrm{CO}_{2}$ excretion after cholesteryl$14 \mathrm{C}$-octanoate was practically identical to that after cholesterol and 14C-octanoic acid, it seems unlikely that lipolysis was the rate-limiting step in the process involving digestion, absorption, and metabolism of cholesteryl octanoate in control animals. It is assumed that in control animals the metabolism of the octanoic acid to $14 \mathrm{CO}_{2}$, rather than hydrolysis, was the important determinant of $14 \mathrm{CO}_{2}$ excretion. However, this was not the case in zein-injected rats, as either feeding of pancreatic enzymes prior to the test meal or administration of hydrolyzed cholesteryl-14Coctanoate fully restored the depressed $14 \mathrm{CO}_{2}$ excretion. Thus, the rate-limiting step was lipolytic digestion, i.e. hydrolysis of the marker molecule, due to the lack of pancreatic enzymes.

Our data suggest that cholesteryl-14C-octanoate can be used as a noninvasive procedure to assess exocrine pancreatic function in experimental animals. The procedure described herein has been modified and in preliminary studies gives similar results in adults with pancreatic exocrine insufficiency (31). In this study, 
cholesteryl-130-octanoate was used successfully, suggesting that the test can be used as a test for pancreatic function in children. A prospective comparison of this new method with other noninvasive tests such as the $P \wedge B \wedge$ or the pancreolauryl test for sensitivity and specificity appears to be indicated.

teknowledgmems. The authors thank I)r. J. Herok. Hoechst $\Lambda$ (i. Fankfurt. West (iermany. for the synthesis of cholesteryl146-octanoate and acknowledge the technical assistance of $\mathrm{Mi}$ chael Buckley.

\section{RIITRI:VCIS}

1. DiMagno I:P. (io VI.W. Summerskill WHJ 197.3 Relations between pancreatic en/yme output and malabsorption in severe pancreatic insufficience. $\backslash$ Engl J Med $288: 813-815$

2. Lankisch PG 198 2 1 xocrine pancreatic function lests (iul 23.777-798

3. Hepner (iW 1978 Breath kests in gastroenterology: Ads Intern Med 23:25-4.5

4. Schwate AI). (ometo F1. Bennetl IR. Mellinkoff SM 1962 Estimation of la absorption by monitoring of expired radioactive earbon dioxide after feeding a radioactive fitt. (jastroenterology 42:285-29)

5. Newcomer AD). Hofmann Al: DiMagno l:P. Thomas PJ (arlson (il 1979 Triolein breath test. A sensitive and specilic test for fat malabsorption (iastroenterology $82: 6-13$

6. Rhodes JB. Arvanitakis ( . Folscroft J 1982 Iong term exocrine pancreatic insufficiency in the at (iastrocnterology 82.1160 (abstr)

7. Imondi $A R$ Stradles $R P$ Wolgemuth $R 1$ 1972 Synthetic peptides in the diagnosis of exocrine pancreatic insufficiency in animals. (iut 1.3:726-731

8. Jover A. (iordon RS 1962 Procedure for quantitative analysis of feces with special reference to fatty acids. J I ab (

9. Somogyi M 1960 Modifications of two methods for the assay of amylase. (lin (hem 6:23-35

10. Imondi AR. Stradley RP. Butler I:R. Wolgemuth RI. 1973 A method for the assay of chymotrypsin in crude biological materials. Anal Biochem 54:199. 204

11. Singleton WS (iray MS Brown MI White Il 1965 chromotographicall homogeneous lecithin from egg phospholipids. J Am ()il ( hem Soc 42:5356

12. Rudd I:A. Brockman HI. 1981 Pancreatic carboxyl ester lipase (cholesterol esterase). In: Borgstrom B. Brockman HI. (eds) I ipases. Flsevier. New York. pp $185-204$

13. Swell I. Boiter TA, Fïld H. Treadwell ( $R$ 1955 Absorption of dictary cholesterol esters. Am J Physiol [80:129-132

14. (ohen M. Morgan (iRII, Ifofmann AF 1980 ) Lipolytic activity of human gastric and duodenal juice against medium and long chain triglvecrides. (iastroenterology $60 \% 1-18$

15. Hamosh $M 1986$ ingual lipase. (iastrocnterologs $90: 1290 \cdot 129$

16. Roberts JM. Montgomery RK. Carey MC 19S4 Rat lingual lipase: Partial purffeation. hodrolvtic properties and comparison with pancreatic lipase Am J Phosiol 247: (j385-C; 393

17. Gallo I. I. (hiang Y. Vahoun (iV. Ireadwetl ( R I980) I ocalization and origit of rat intestinal cholesterol esterase determined by immunecylochemistry. l.ipid Res 21:537-545

18. I ankisch P(i Schreiber A Otwo 1 1983 Pancreolaurs test Paluation of tubeless pancreatic function test in comparison with other indirect and direct tests for exocrine pancreatic function. 1) ig I) is Sci $28: 49()+493$

19. Mever-Bertenrath Je. Heckmann (i, Kaftarnik H 1978/ar Biocheme un klinischen Bedeutung des oralen Pankreasfunktionstests mit Huoresceind laurinsiurcester. Klin Wochensehr $56,-4) 179 ? 0$

20. Thomson ABR and Dietsehy JM 198 I Intestinal lipid absorption. Mator extracellular and intracellular crents. In: Johnson I R (ed) Physology of the (iastrointestinal Tract. Rasen Press. Vew Yorh. pp 1147 1220

21. Schwabe AD). Bennett I.R. Bowman I.P 1964 Octanoie acid absorption and oxidation in humans. J Appl Phosiol 14:3.35-3.37

22. Kivasu J) Bloom B. (haikofl Jl 1952 The portal transport of absorbe 1 tate acids. J Biol (hem 199:415

23. Circenherger $\mathrm{VJ}$. Shilman TC 1969 . Medium chain triglyecrides physiologieal considerations and clinical implications. I Ingl J Med $28(8: 104$

24. I ang ( ( Fir K. Borer P. Kavasseh I Stadler (i. I980 D) Prufung der exokrinen Pankreasfunktion mit oral verabreichter V-Benzost-1-Tyessl. Paraaminohenzoesaure (BT-P.ABA-Test). Standortbestimmung nad s S Jahren Erfahrungen in der Klinik. Schweir Med Wochenschr $110: 522.528$

25. Sterchi FI: (ireen JR. Iente M11 1983 Vonpancreatic Hodrolssis of $V$ Benzoyl-I-tyrosid-p-aminobenzoic acid (PABA pepticie) in the rat smal intestine I Pediatr (iastroenterol Vute $2.539-547$

26. (jur K. Felsenfeld (). Imondi AR 1978 (humotropsin-like activity of some intestinal backeria $\mathrm{Am}$ J Dig Dis 23:41,3-416

27. Abdulla M. Anderson B. Fvander A 1978 Zine and copper concentration in serum. blood and liver in moderate experimental pancreatx insullicienes. Digestion 18:86-92

28. Mundlos S. Schaar 11. Koop I. Adler (i. Amold R 1986 f vocrinc pancreati function in olecicad induced pancreatic insufficiency in rats. Pancreas $1: 24$ 36

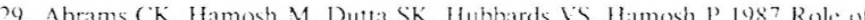
nonpancreatic lipolstic activits in esocrine pancreatic insufficiencs (iastreenterology $92: 125-129$

30. Jensen R( C. Clark RM. deJong FA. Hamosh M. L iaw I. Meth VR I98? The lipolytic triad: Human lingual. breast milh and pancreatic lipases: Phosiological implications of their characteristics in digestion of dictary fats 1 Pediat (iastroenterol Viut 1:2+3-25s

31. Cole S. Rossi S. Stern A. Hofmann AF The cholesters! octanoate breath fest Preliminary studies on a new non-invasice test of human pancreatic exocrine function. Gastrocnterology (in press) 